\title{
Re emergence of old infection nipah virus
}

\begin{abstract}
Since the last 3 decades new infection including the re-emergence of old infections have become a public health concerned as they tend to became pandemic with serious implication for the socio-economic and socio-political scenario of the global community. The facilitating factors include urbanization and destruction of natural habitats, climate change and changing ecosystems, changes in population of reservoir hosts or intermediate insect vectors and microbial genetic mutation, international trade and commerce, change in human demographics and behavior, lack of public health services and infrastructure, and antibiotic resistance.
\end{abstract}

Keywords: Henipavirus, nipah virus, environment, host
Volume 6 Issue 6 - 2018

\author{
Subhashish Das \\ Department of Pathology, Sri Devaraj Urs Medical College, India
}

Correspondence: Subhashish Das, Department of Pathology, Sri Devaraj Urs Medical College, Tamaka, Kolar, Karnataka, India, Email sdes15150@gmail.com

Received: July II, 2018 | Published: December 14, 2018

\section{Introduction}

According to WHO Re-emerging infectious disease "Infectious agents that have been known for some time, had fallen to such low levels that they were no longer considered public health problems \& are now showing upward trends in incidence or prevalence worldwide or have appeared in areas where they were not previously found". ${ }^{1}$

\section{Factors contributing to emergence}

Agent: (1) Evolution of pathogenic infectious agents,(microbial adaptation \& change), Mutations. (2) Development of resistance to drugs. (3) Resistance of vectors to pesticides. ${ }^{2}$

Host: (1) Human demographic change (inhabiting new areas), increase contact with animals and natural environment. (2) Human behaviour (sexual \& drug use- sharingneedles, drug abuse, body piercing),Human susceptibility to infection,(Immunosuppression)- stress and lifestyle changesNutritional changes, more use of pesticides. ${ }^{3}$

Environment: Climate \& changing ecosystems, Economic development \& Land use,(urbanization, deforestation) Technology \& industry (food processing \&handling), Changes in agricultural \& food production,patterns- food-borne infectious agents (E. coli) (Figure 1) ${ }^{4}$

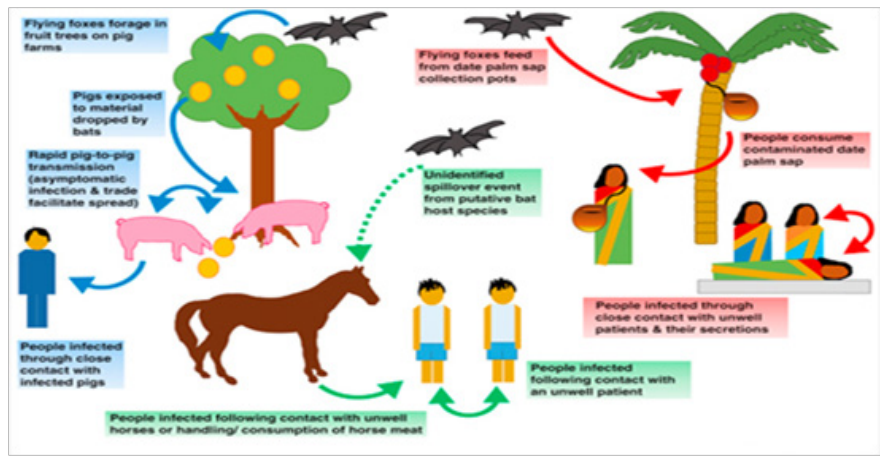

Figure I Routes of transmission, Malaysia to Kerala.

Hence according to the World Health Organization (WHO), infectious and parasitic diseases constitute the second most lethal cause of mortality (death) globally after cardiovascular diseases, implicated in $26 \%$ of deaths in $2002 .{ }^{5}$ Re-emergent infections have gained renewed virulence (the degree to which an organism can cause disease) due to other emerging or chronic diseases that impair the immune system (e.g., HIV/AIDS, diabetes, cancer) or the spread of antibiotic, antiviral, and anti-fungal medication resistance. In addition, there is the threat of re-emergent infectious disease that is intentionally spread in connection with bioterrorism, as occurred in the United States in the anthrax attacks of 2001. Although the numbers of people infected and killed were small in these attacks, the potential for widespread targeted assaults make the use of bioterrorism agents especially disturbing to consider. ${ }^{6}$

Etiology: Nipah virus was first identified in Malaysia in the year 1978 and considered to be a variant of Japanese Encephalitis it is so called after the village of "SungaliNipah" where it was first identified. Nipah is an envelope, negative sense, single-stranded RNA virus, with a genome sequence size of about 18,000 nuclcotides. NiV genome organization comprises six major genes present in all Paramyxovirus. Fruit bats (Macrochiroptera) of the family Pteropodidae particularly species belonging to the Pteropus genus- are the natural hosts for Nipah virus. ${ }^{?}$

\section{Epidemiology}

It presents the variable picture. In Singapore it was associated with importing and slaughter of imported pigs from Malaysia were as in Malaysia the diseases progressed from the natural host "Fruit Bats" to amplification host (livestock) and finally to humanswhere as in Bangladesh it was due to the consumption of fruits and fruits products (raw date pam sap) contaminated with urine or saliva from infected fruit bat. In India, some cases human to human transmission has been reported. ${ }^{8}$ In most Nipah outbreaks in South Asia, the virus has displayed a "stuttering chain of transmission", meaning that once the virus spreads from fruit bats to humans, it moves mainly to people in close contact with patients, such as family, hospital staff and caregivers. In this picture, nursing staff of Kozhikode medical college wear masks.

\section{Clinical features}

The Nipah virus infection causes influence like symptoms of high fever, headache, myalgia, sore throat, weakness along with nausea and vomiting. ${ }^{9}$ The infection has aincubation period of around 2 weeks to 4 weeks. Occasional case have been reported of having a typical pneumonia and acute respiratory distress syndrome. Autopsy finding are predominantly involving the CNS (Figure 2). ${ }^{10}$

The important features of Nipah virus genome include

I. Viral proteins: fusion protein ( F) and attachment glycoprotein protein $(\mathrm{G})$

II. Phosphoprotein (P): it role as a polymerase cofactor, enhancing polymerase processivity and allowing the encapsidation of the newly synthesized viral genomes and antigenomes. 
III. Phosphorotein of Nipah virus has an additional role in immunosuppression: blocking interferon signaling by binding host STAT-1.

IV. Nipah virus ( $\mathrm{NiV}$ ) is a RNA virus belongs to family Paramyxoviradae and genus Henipavirus.,Size: 40-600nm,Shape: pleuromorphic, Envelope: present

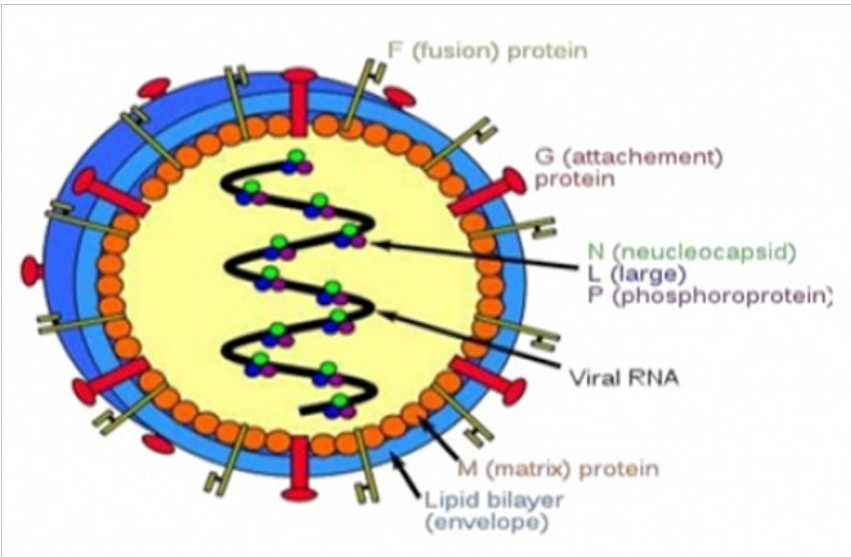

Figure 2 Genome of Nipah Virus.

Diagnosis: RT-PCR is the main mode of diagnosis serum Neutralisation $(\mathrm{SN})$ tests can also be done.

Treatment: Symptomatic treatment is mainly done as currently no antiviral drugs or vaccines available to treat Nipah virus infection for either people or animals

\section{Recent events in India}

The outbreak of Nipah virus in Kerala presents to us several lessons in infectious diseases. Importantly the detection of disease depends on old fashioned clinical skills. The three patients from the same family were admitted to the baby memorial hospital in Calicut. The family had recently changed residence to a new house where there was an abandoned well. ${ }^{11}$ Hoping to clear the well for use, two boys of the house descended but were scared away by a bat colony residing there. Sub-sequently the boys and their father fell ill and were taken to the local hospital in Perambra where they were attended to by nurses of whom three were infected and one nurse died. The patients were evaluated at $\mathrm{BMH}$ and right away zoonotic viral encephalitis was suspected. CSF and Blood sampled were sent to the Institute of Virology Alleppey and also to Manipal where Nipah was first suspected and confirmed by the Pune Virology Institute. ${ }^{12}$

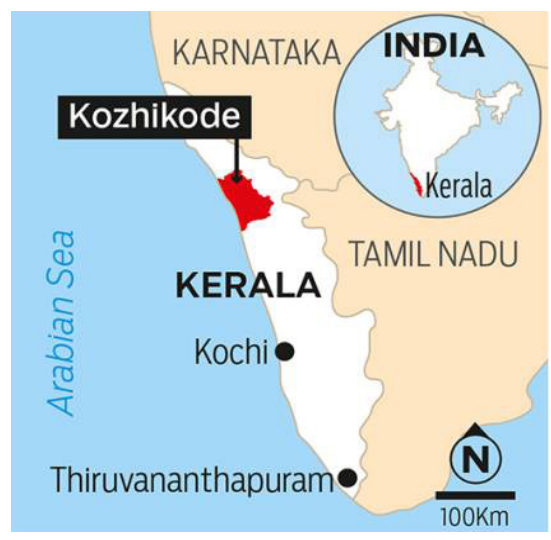

a. Prompt and extraordinary response of the local population and local health authorities to meet the challenge. This was prompted by high literacy rate among the local population, better health infrastructure, adequate resources allocation coupled with mass awareness campaign etc launched by the stake authorities helped in "containing" the epidemic at a relatively earlier stage, unlike the once which had happened earlier in North Bengal and Bangladesh

b. High index of suspicion regarding the possibility of Nipah virus among the local doctors along with the prompt support and correct guidance provided by the Manipal Center of Virus Research enabled the medical fraternity to reach an earlier scientific breakthrough.

c. India has a poor record of outbreak investigations. About 10,000 people develop encephalitis-like symptoms each year but never get a diagnosis. Some regions, such as Uttar Pradesh's Gorakhpur and Bihar's Muzaffarpur, saw thousands of deaths in repeated annual outbreaks before the causes were established. Against this background, the discovery of an exotic pathogen in the very second patient hit by an outbreak, as was the case in Kozhikode, has few precedents.

Prevention of emerging infectious diseases: It consists of the following measures, namely, Surveillance and Response, Applied Research, Infrastructure and Training, Prevention andcontrol. ${ }^{13}$

\section{Conclusion}

Whole genome sequencing of Nipah virus along with the establishment of BSL-4 laboratory is essential for managing future epidemics and also providing rapid and effective confirmative diagnosis. $^{2}$ Commitment to technology transfer and global collaboration is essential if we are to have the agility required to keep pace with emerging infectious diseases. Pathogen surveillance and discovery can promote global interaction via collaborations on matters that know no national orpolitical boundaries but simply reflect our common goals. ${ }^{14}$

\section{Acknowledgments}

None.

\section{Conflicts of interest}

There is no conflicts of interest among the authors.

\section{References}

1. Leroy EM, Kumulungui B, Pourrut X, et al. Fruit bats as reservoirs of Ebola virus. Nature. 2005;438:575-576.

2. Towner JS, Pourrut X, Albariño CG, et al. Marburg virus infection detected in a common African bat. PLoS One. 2007;2(8):e764.

3. Li W, Shi Z, Yu M, et al. Bats are natural reservoirs of SARS-like coronaviruses. Science. 2005;310:676-679.

4. Das. S. Blood Safety: New challenges \& Opportunities in Developing Nations. J Bacteriol Mycol. 2017;4(5):146-148.

5. Chua KB, Crameri G, Hyatt A, et al. A previously unknown reovirus of bat origin is associated with an acute respiratory disease in humans. Proc Natl Acad Sci USA. 2007;104:11424-11429.

6. Lu G, Liu D. SARS-like virus in the Middle East: a truly bat-related coronavirus causing human diseases. Protein Cell. 2012;3(11):803-805. 
7. Das S, Harendra Kumar ML. Distribution of ABO \& Rh Blood Groups among Blood Donors of Kolar: A 5 Years Study. Journal of Clinical and Biomedical Science. 2013;3(2):55-59.

8. Chua KB, Bellini WJ, Rota PA, et al. Nipah virus: recently emergent deadly paramyxovirus. Science. 2000;288(5470):1432-1435.

9. Chua KB. Nipah virus outbreak in Malaysia. $J$ ClinVirol. 2003;26(3):265-275.

10. Field H, Young P, Yob JM, et al. The natural history of Hendra and Nipah viruses. Microbes Infect. 2001;3(4):307-314.
11. Lamb RA, Parks GD. Paramyxoviridae: The viruses and their replication. In: Knipe DM, Griffin DE, editors. Fields Virology. Lippincott Williams \& Wilkins, Philadelphia. 2007. p. 1449-1496.

12. Eaton BT, Broder CC, Middleton D, et al. Hendra and Nipah viruses: different and dangerous. Nat Rev Microbiol. 2006;4(1):23-35.

13. Pallister J, Middleton D, Broder CC, et al. Henipavirus vaccine development. J Bioterror Biodef. 2011;S1:005.

14. Das S. Emerging Infections in Pregnancy. $J$ Bacteriol Mycol. 2017;5(7):442-445. 